\title{
Predicting Alzheimer's and heart disease
}

\author{
Fiona Godlee editor in chief, The BMJ
}

New research released this week has identified a set of proteins that predict with a fair degree of accuracy whether early symptoms of memory loss will progress to Alzheimer's disease (doi:10.1136/bmj.g4506). How much closer this brings us to a clinically useful blood test is hard to judge. And, as Krishna Chinthapalli explains this week (doi:10.1136/bmj.g4433), progress towards effective treatments for Alzheimer's continues to be painfully slow.

Chinthapalli presents three main theories for what causes Alzheimer's. Of these, the cholinergic hypothesis has borne most fruit in terms of drug treatment. But even so, no new drug has been licensed for the treatment of Alzheimer's since 2002. A second theory-that Alzheimer's is caused by amyloid protein-has failed to generate treatments, leading some to question its validity. The third-that Alzheimer's is caused by an insoluble protein, hyperphosphorylated tau-is the subject of several ongoing trials.

In the absence of effective treatments, why go to any lengths to identify people at risk? Chinthapalli explains that, without accurate predictive biomarkers, research will continue to stumble. Up to a quarter of participants in a phase III trial this year are thought to have been misdiagnosed, he says.

Telomere length has been proposed as a possible predictive biomarker for cardiovascular disease. Our editorialists (doi:10. 1136/bmj.g4373) hail the systematic review by Philip Haycock and colleagues (doi:10.1136/bmj.g4227) as the most authoritative statement on this link available today. But they conclude that it's too early to use telomere length as a biomarker. They also resist the tempting idea that shortened telomeres, and the resultant cellular aging, might be a cause rather than just a predictor of coronary heart disease.

Disentangling association from causation is the holy grail of observational epidemiology. As Maria Glymour writes in her editorial (doi:10.1136/bmj.g4334), mistaking predictive associations for cause and effect could lead us to confiscate matchboxes as a strategy to prevent lung cancer. New methods are emerging but remain controversial. Mendelian randomisation is one such (doi:10.1136/bmj.e7325). It has the potential to minimise bias in observational studies by using genetic variants to simulate randomisation.

Holmes and colleagues used Mendelian randomisation in a study published this week to explore the link between alcohol consumption and cardiovascular risk (doi:10.1136/bmj.g4164). They found that people who carry a genetic variant that leads them to drink less alcohol had a reduced risk of coronary heart disease. The authors say this indicates that drinking less alcohol, even among light to moderate drinkers, reduces cardiovascular risk.

In her linked editorial Glymour is more circumspect. She thinks that the "provocative and innovative" analysis can't establish such a claim. But she ends on a positive note. "Combining evidence from multiple research designs ... will prove enlightening in the long run, even if conclusions are puzzlingly inconsistent and difficult to interpret in the short run. Truly novel studies, such as the study by Holmes and colleagues, are therefore critical contributions to the research base."

Cite this as: BMJ 2014;349:94528

๑) BMJ Publishing Group Ltd 2014 